\title{
Integrated Sensor Systems for Smart Cities
}

\author{
Željko BAČı́́, Tomislav JOGUN, Ivan MAJIĆ
}

\begin{abstract}
Smart cities are ubiquitous topic today, and emerge as preferred concept for future development of human lifestyle. In the international literature, there are only a few articles dealing critically with the topic of the smart cities, and even fewer of them are interdisciplinary. Integrated sensor systems are a prerequisite for developing the concept of smart cities in practice because individual sensors can hardly meet the demands of the smart cities for complex information. This paper provides an overview of the theoretical concept of smart cities and the integrated sensor systems. The article promotes an interdisciplinary approach to the study of the smart cities, where geomatics should also contribute due to the fact that most of the information has a spatial component.
\end{abstract}

Keywords: development; sensor; smart city; system

\section{Introduction}

The phrase "smart city" is becoming ubiquitous in the political, economic, scientific and colloquial discourse. In most cases, the positive effects of smart cities on the environment and people are emphasized, imposing the concept of smart development as one of the best solutions for the future challenges that endanger humanity. Integrated sensor systems are the first step in the development of the concept of smart cities. The aim of this article is to provide a critical review of the issue of sensor systems within smart cities.

\subsection{Terms and Definitions}

The term "smart city" is similar to the concepts of intelligent city, digital city, information city, e-city, virtual city, cyber-city, global city, network city, digital community, smart community, etc. $[1,2]$. Spatially considered, the smart city is apart of a broader approach of "smarter planet", tailored to specific urban areas [3]. On the other hand, smaller territorial units of the smart cities are "smart homes" $[4,5]$. Out of several definitions of smart cities given in the terminology, the following one has been chosen: smart city is "the safe, secure, environmental and efficient urban centre of the future with advanced infrastructures such as sensors, electronic devices and networks to stimulate sustainable economic growth and a high quality of life" [6].

A sensor is a device that converts physical parameters into an electronic signal, which can be interpreted by humans or can be stored in autonomous system. These signals for conventional sensors include among other things light, pressure, temperature, humidity and various other parameters [4].

Integrated sensor systems include the use of multiple complementary sensors within Micro-Electro-Mechanical Systems (MEMS) [7]. Apart from the internal connecting of sensors, in the context of smart cities, it is important to externally connect them via wireless network to a central unit that receives and processes data, so they are called wireless sensor networks [8]. That is important because cities are too complex for a single type of sensor needed to satisfy the demands for information necessary for smart management [2].

\subsection{The Origin of the Smart City Concept}

During the last few decades, the world has been facing expansive urbanization and population growth. In $2010,50 \%$ of the world's population lived in the cities on just $1 \%$ of the planet's land area, and this figure is expected to rise to $75 \%$ or 6 billion people by 2050 [2, 4, $6]$. Due to the growth of cities, there will be even greater economic disparities in the world. Resource shortages, climate changes and environmental pollution will be more serious at the global level [4]. Cities will be especially vulnerable due to high concentration of the population, which will increase pressure on resources such as land, space, clean water and energy [9]. A particular challenge will be effective management of large cities and providing the basic functions to the citizens, such as transport, security, water supply and energy. The answer to these challenges is the development of smart cities based on information technologies. The use of technology in smart cities would lead to the reduction in consumption of energy, water and $\mathrm{CO}_{2}$ emissions. It would improve the use of existing infrastructure, provide new services to citizens and increase the quality of life [10].

However, there is a different perspective related to the origin of the concept and to the need for smart cities. Although the concept of "smart growth" has existed ever since the late 1990s, the most significant progress in the popularization of smart cities took place after the global financial crisis in 2008. At that time, IBM recognized the valuable market for its computer products as many cities have shown interest in economic development, while earlier mentioned motives were secondary. In fact, during the financial crisis in 2008-2009, the cities realized that they had to compete with other cities as never before. It wasn't just the competition with their neighbors at the regional or national level, but - as a result of the Internet and global supply networks - competition with peers across the world. And it wasn't only competition for investment and jobs, but for the Generation $Y$ and Generation Z people (cohort of people born after 1980's) who they hoped would be the developers of new economic strength. Their interest in smart cities is actually related to their own branding or image and their ability to attract these people, so-called "creative class" [10]. 
According to these arguments, both aspects related to the origin of the smart city concept are partially correct.

\subsection{The Elements of Smart City}

Authors in [9] divided the definitions of smart cities from reviewed literature into two levels. One notion is that smart cities are a form of intelligent and sustainable urban development based on the concept of smart growth. The second group of papers considers smart cities as a technological phenomenon. Given that the approach of this study coincides with the latter, this approach will be explained in more detail.

The technological architecture of smart cities is linked to the Information and Communication Technology (ICT), the Internet of Things (IoT), Wireless Sensor Network (WSN) and others. The layers of the technological architecture of smart cities / IoT are: 1) sensors, 2) network and 3) applications. Sensors collect data through the network and send them to a central processing unit, on the basis of which decisions are made relating to the application layer $[3,5]$. As a separate layer of the architecture, platform can be added,where the data are processed [9] (Fig. 1).

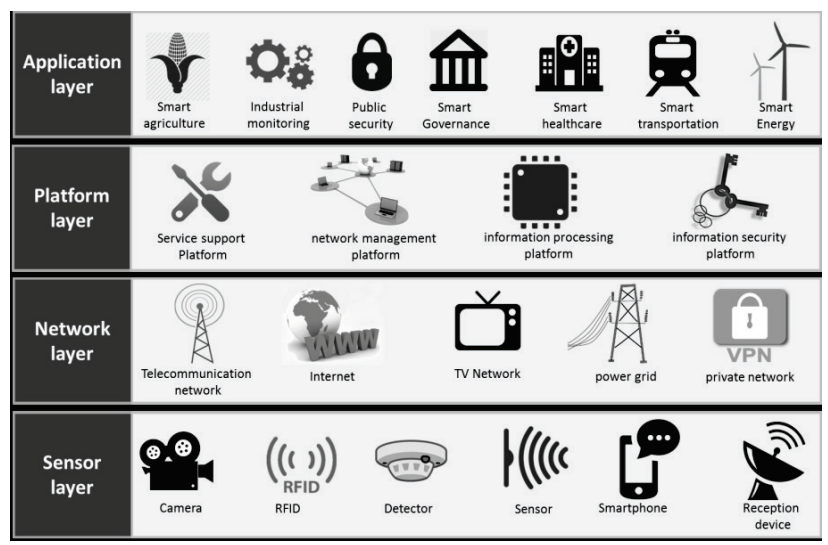

Figure 1 Technological architecture of smart cities [9]

Different schema of the smart cities' technological architecture can be found in [11], which includes the interactions between actors in smart cities: citizens, municipality departments and service providers. Sensors and networks are put under the infrastructure of smart cities (Fig. 2).

Application layers are urban systems or dimensions that require smart management. Their number is often between three and eight, depending on the authors to whom the reader is referred [4, 9, 10, 12, 13, 14, 15].

The model proposed by the scientists from IBM decomposes cities in five application layers: the natural environment, infrastructure, resources, services and social systems. Each layer is more comprehensively classified [10] (Fig. 3).

A simpler model of urban system is proposed in [13], which consists of three broad components: economic, social and environmental. The economic component includes public administration and economic actors, the environmental component includes resources and managerial infrastructure, and the social component is composed of citizens. The elements of smart city are linked by ICT (Fig. 4).

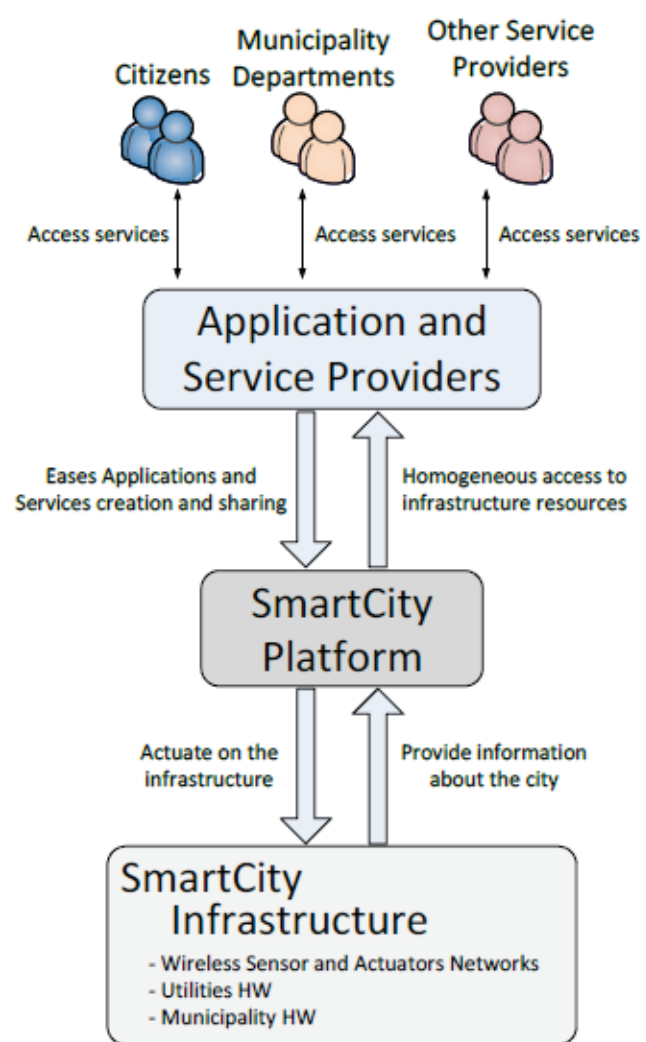

Figure 2 Smart city actors interactions [11]

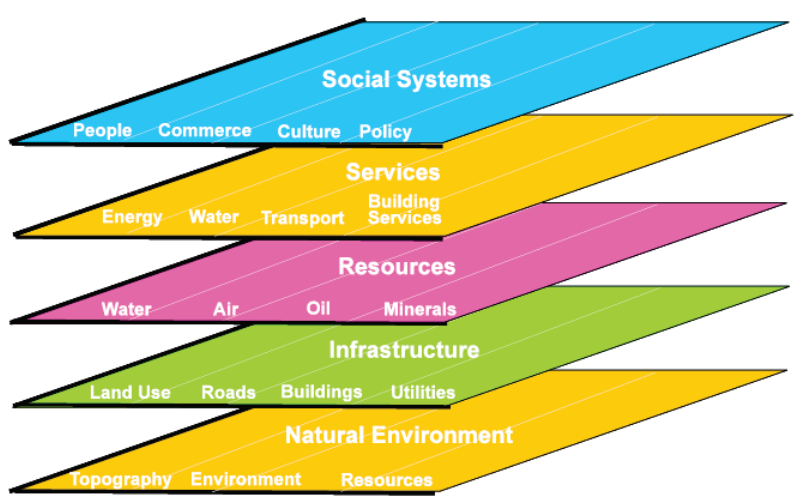

Figure 3 Application layers in smart cities [10]

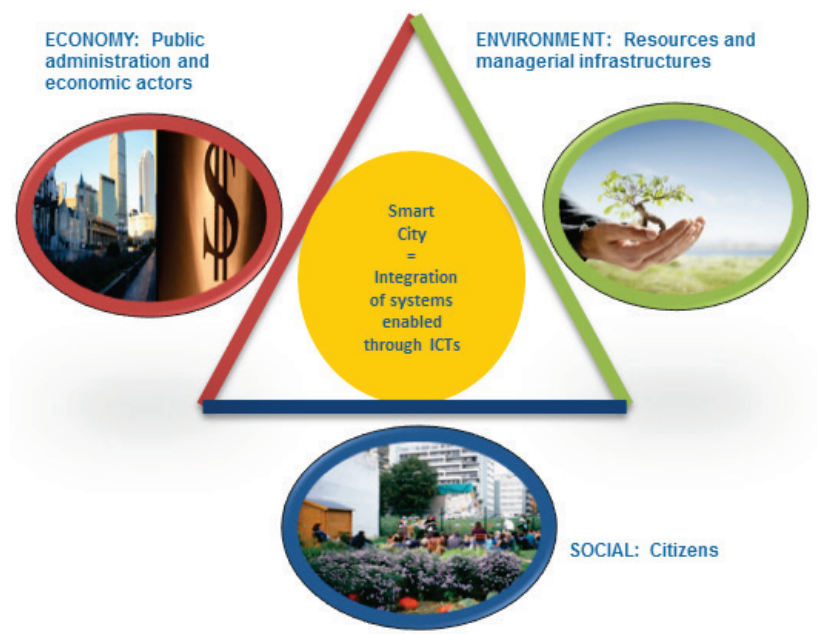

Figure 4 Application layers in smart cities [13] 
Table 1 Examples of sensors used for quantifying context to derive contextual information. Terms, related terms, characteristic context parameters, and application fields for different types of sensor [14]

\begin{tabular}{|c|c|c|}
\hline Term & Related Terms & $\begin{array}{c}\text { Characteristic Context } \\
\text { Parameters, and Application } \\
\text { Fields }\end{array}$ \\
\hline \multicolumn{3}{|c|}{ Technical Sensors - in Situ Sensors } \\
\hline $\begin{array}{l}\text { Environmental } \\
\text { Sensors }\end{array}$ & $\begin{array}{l}\text { Environmental } \\
\text { monitoring, } \\
\text { urban } \\
\text { Sensing }\end{array}$ & $\begin{array}{l}\text { Meteorology and weather } \\
\text { Air pollution/quality } \\
\text { monitoring } \\
\text { Heat island detection } \\
\text { Flood monitoring } \\
\text { Nuclear radiation safety }\end{array}$ \\
\hline Mobile sensors & $\begin{array}{l}\text { Wearable } \\
\text { ambient sensors, } \\
\text { mobile } \\
\text { sensor web }\end{array}$ & $\begin{array}{l}\text { Ubiquitous measurements, } \\
\text { e.g., through bike-mounted } \\
\text { sensors } \\
\text { Disaster management } \\
\text { Embedded mobile sensor } \\
\text { web, application- } \\
\text { independent }\end{array}$ \\
\hline $\begin{array}{l}\text { Pervasive } \\
\text { sensing }\end{array}$ & $\begin{array}{l}\text { Ubiquitous } \\
\text { sensing, socially } \\
\text { aware computing }\end{array}$ & $\begin{array}{l}\text { Smart and aware } \\
\text { environments and homes and } \\
\text { ambient/active assisted } \\
\text { living } \\
\text { Pervasive healthcare } \\
\text { RFID-based location and } \\
\text { tracking } \\
\text { Socially aware computing }\end{array}$ \\
\hline \multicolumn{3}{|c|}{ Technical Sensors - Remote Sensors } \\
\hline Remote sensors & $\begin{array}{l}\text { Remote technical } \\
\text { sensors and } \\
\text { remote sensing } \\
\text { systems, from } \\
\text { satellite-based to } \\
\text { terrestrial }\end{array}$ & $\begin{array}{l}\text { "Classic" airborne and } \\
\text { spaceborne optical systems } \\
\text { New developments: high } \\
\text { resolution, hyperspectral, } \\
\text { LiDAR, UAV } \\
\text { Thermal } \\
\text { Atmosphere/Aerosols }\end{array}$ \\
\hline \multicolumn{3}{|c|}{ Human Sensors } \\
\hline $\begin{array}{l}\text { People as } \\
\text { sensors }\end{array}$ & $\begin{array}{l}\text { Citizens as } \\
\text { sensors, citizen } \\
\text { sensing, human } \\
\text { sensing, human } \\
\text { sensors, humans } \\
\text { as sensors, } \\
\text { physiological } \\
\text { sensors, wearable } \\
\text { body sensors, } \\
\text { participatory } \\
\text { sensing, } \\
\text { Volunteered } \\
\text { Geographic } \\
\text { Information } \\
\text { (VGI) }\end{array}$ & $\begin{array}{l}\text { Flood monitoring } \\
\text { Generic participatory } \\
\text { sensing and sensing } \\
\text { platforms (for smart cities) } \\
\text { Physiological parameters } \\
\text { such as pulse, oxygen } \\
\text { saturation, stress levels } \\
\text { Disaster and incident } \\
\text { management } \\
\text { Noise mapping } \\
\text { VGI in general and in some } \\
\text { of the above mentioned } \\
\text { examples (including } \\
\text { postings in social media } \\
\text { regarding public health, air } \\
\text { quality etc.) }\end{array}$ \\
\hline $\begin{array}{l}\text { Collective } \\
\text { sensing }\end{array}$ & $\begin{array}{l}\text { Mobile phone } \\
\text { sensing, crowd } \\
\text { sensing, social } \\
\text { sensing, online } \\
\text { sensing, social } \\
\text { media }\end{array}$ & $\begin{array}{l}\text { Disaster and incident } \\
\text { management } \\
\text { Mobility patterns and } \\
\text { transportation } \\
\text { Socio-physical context } \\
\text { estimation } \\
\text { Tourism } \\
\text { Epidemiology and disease } \\
\text { detection }\end{array}$ \\
\hline
\end{tabular}

\subsection{Performance Evaluation in Smart Cities Projects}

The smart cities concept is still too extensive and complex to be fully developed on the entire urban structures. Thus, the most usual way of smart cities development in practice is through the projects oriented on some particular city elements. These projects are very diverse, and in this context, performance evaluation in the smart cities projects is highly dependent on the problem which is tackled by the specific project. Therefore, there are no standardized key performance indicators for the evaluation of the expected effect which certain project should achieve for the city management or citizens quality of life, meaning that specific key performance indicators should be developed for each project.

The similar statements can be found in [16], where an in-depth overview of the key performance indicators of smart cities in Europe is given. It has been noticed that smart cities ranking criteria cannot be unique on the global level, as it depends on authors and sponsors, databases, usage of indicators, spatial dimensions and elaborateness of results.

\section{INTEGRATED SENSOR SYSTEMS FOR SMART CITIES}

Sensors are a crucial component of any intelligent control system. A process is improved based on its environment and to make a control system aware of its environment, it is typically equipped with an array of sensors from which it collects the required data. Furthermore, it uses the appropriate variables to characterize its environment and adjust its operations accordingly [4]. Some other authors claim that smart cities are often pictured as constellations of instruments across many scales that are connected through multiple networks which provide continuous data regarding the movements of people and materials in terms of the flow of decisions about the physical and social form of the city [12].

The importance of sensor systems for smart cities can also be seen in the smart city conceptual models, where they are often suggested as the first layer of a smart city model $[9,11,17]$.

Sensors have to be deployed in large numbers and they have to be interconnected, so that the collected data can be sent to a central information system, where intelligent decisions based on this data can be made. This poses a number of challenges. Firstly, there needs to be a communication infrastructure in place for these sensors to communicate with each other. Secondly, what is the most efficient way to aggregate and process this data? $[4,17]$

\subsection{Sensors for Information Collecting}

In today's concepts and terminology used in urban geo-sensing, sensors can be divided into three categories: in situ technical sensors, remote technical sensors, and human sensors (Tab. 1). These three categories overlap to a certain degree so they are not always easily distinguishable from each other. The difference between in situ and remote technical sensors is that in situ sensors are measuring in the immediate surroundings of the sensor, while remote technical sensors are, as the name suggests, measuring at a distance. Human sensor data are collected by human-generated measurements. These include subjective observations on the environment, social media posts, mobile phone calls and text messages, and physiological measurements by wearable body sensors. This definition implies a clear distinction between humans that generate data and humans that carry "ambient sensors" to measure external parameters (e.g. measuring air quality with a mobile sensor) [14]. 
There is a widely accepted idea that sensors should be implemented in a form of sensor nodes. It is a number of sensors that can share the same power source, communication and processing unit. In such a way, it is possible to gather various information from multiple sensors at the same location. Because of a big number of sensor nodes that should be installed in a smart city, it is important to pay attention to their size and energy demand $[4,8,9,11,15,18,19]$.

Geomatics also plays an important role in sensors and sensor systems for smart cities. For the majority of sensor measurements, in addition to their quantitative and qualitative components, it is necessary to determine the spatial component in order to provide complete information that will then serve to make decisions, and maybe even display the data to end users based on their spatial components. Apart from the spatial support for other data, there are many other spatial embedded questions arising in cities that need to be answered in a smart way (Tab. 2), and the most frequently suggested solution today is the use of GNSS devices [13, 20].

Table 2 Spatially embedded questions arising in projects to make the city smarter [13]

\begin{tabular}{|l|l|}
\hline \multicolumn{1}{|c|}{ Spatially embedded questions } & \multicolumn{1}{c|}{ Information required } \\
\hline Where is this? & Location \\
\hline What is happening where? & Event at a location \\
\hline Is this available here? & $\begin{array}{l}\text { Presence of a thematiccontent } \\
\text { at a location }\end{array}$ \\
\hline What is the amount of this here? & Statistics per location \\
\hline $\begin{array}{l}\text { What is the amount of this per } \\
\text { time unit? }\end{array}$ & Data flow per location \\
\hline What is the best route? & Routing \\
\hline What is here? & Spatial content of an area \\
\hline What was here? & $\begin{array}{l}\text { Historical spatial content of an } \\
\text { area }\end{array}$ \\
\hline $\begin{array}{l}\text { What will be the impact of doing } \\
\text { this here / of this event occurring } \\
\text { here? }\end{array}$ & $\begin{array}{l}\text { Simulation of the interaction of } \\
\text { an event with the spatial } \\
\text { content of an area }\end{array}$ \\
\hline Can I do that here? & $\begin{array}{l}\text { Correlation between an action } \\
\text { and the spatial content of an } \\
\text { area }\end{array}$ \\
\hline
\end{tabular}

\subsection{Connecting the Information}

Communication technologies have a significant role in a smart city infrastructure. It is logical that, because of the feasibility and cost-effectiveness, priority is given to communication technologies that have already been developed and are widely used. Because of that, the most frequently mentioned technologies are $3^{\text {rd }}$ Generation (3G), Longterm Evolution (LTE), Wireless fidelity (Wi-Fi), Worldwide Interoperability for Microwave Access (WiMAX), ZigBee, Cable Television (CATV), Dash7, Near Field Communication (NFC), Radiofrequency identification (RFID) and Satellite communications $[4,15,21,22]$.

Depending on the area they cover, they are usually divided into Home Area Network (HAN), Wide Area Network (WAN) and Field Area Network (FAN). HAN includes technology that allows data transmission at short distances, such as ZigBee, Dash7, Wi-Fi or network technologies such as Ethernet. All the monitoring and control system's components in a home are connected by the HAN. WAN includes technology that allows data transmission over longer distances than the HAN, and that provides communication between service providers and end users. FAN is commonly used in a smart grid to connect customers' premises to infrastructure substations [4].

When talking about the connection between the sensor nodes, the Internet of Things (IoT) concept is also very important. It refers to the interconnection of uniquely identifiable embedded computing like devices within the existing Internet infrastructure. Typically, IoT is expected to offer advanced connectivity of devices, systems, and services that goes beyond machine-to-machine communications (M2M) and covers a variety of domains, and applications. According to the IoT concept, sensor nodes should be energy efficient and wirelessly connected to form a Wireless Sensor Network (WSN). This would be a way to avoid the high costs and problems that arise from installation of the network cables $[4,5,11,14,15$, $17,22,23]$.

\section{APPLICATIONS OF THE INTEGRATED SENSOR SYSTEMS}

\subsection{Smart Transport and Mobility Tracking}

With the rapid growth in the number of cars over recent years, there is an increasing need for efficient transport management, in order to avoid traffic jams and optimize traffic flows, especially at intersections [4]. As smart cities prevail with an increasing capability to be instrumented with a diverse range of mobile and fixed sensors, connected via wireless and wired networks, these in turn enable a richer set of smart city Intelligent Transport System (ITS) services. Such services include adaptive personalized maps, adaptive vehicle navigation, smart fleet management and traffic monitoring, road incident detection, congestion avoidance, speed control via smart interaction with roadside controls, contextbased vehicle maintenance, car parking aids, human driver monitoring and better driving safety [23].

A conventional way to regulate traffic flow is by the use of traffic lights. These typically have fixed switch interval times, which are not adjustable to traffic conditions. Traffic jams have significant impacts on fuel consumption due to the frequent starts and stops, as well as increased carbon emissions. An adaptive scheme, dependent on traffic conditions, is more desirable. In this context, a method to estimate the number of cars approaching an intersection could generate information for switch interval times to be dynamically adjusted based on traffic conditions. For such an intelligent system to be realized, efficient methods to detect traffic (i.e., count the number of cars) are required. There have also been proposed smart intersections without traffic lights and stop signs. In that approach, wirelessly interconnected vehicles can communicate with each other and use decision-making for collision avoidance.

Cheap methods of sensing cars involve induction loop detectors which are buried in roads. Loops detectors can be used to detect the presence of metals, which is interpreted as a vehicle. Moreover, they can enable an estimate the kind of vehicle which has been sensed, its speed or other parameters, which can be useful for traffic flow management. To estimate a vehicle's weight, other 
methods such as weight in motion (WIM) can be used, whose sensors (e.g. piezoelectric systems, capacitive mats, bending plates, load cells, and optical WIM) are mounted on road surfaces. These highlighted methods usually carry high installation and maintenance costs.

Less intrusive (but not as accurate) and more sophisticated methods involve video cameras. These approaches are more attractive mainly because cameras can be easily installed and the level of required maintenance is low, compared to previously described approaches. Furthermore, in the instances where surveillance cameras are already installed, these can be used for intelligent transportation applications. The system which consists of multiple standard CCTV cameras and personal computers (PCs) was tested in different environments (e.g. airports and tunnels). The main drawback of computer vision-based methods is their performance dependency on environment conditions, such as lighting, occlusions and weather. For night-time scenario, street lamps and traffic lights can be used for vehicle sensing, as vehicles can be detected by considering the distance between vehicle's headlights [4].

Apart from vehicle detection, smart cities use mobility data recorded by integrated sensor systems. A system using such data is M-Atlas, which is focused onto the concept of a trajectory, i.e., a sequence of timestamped locations, sampled from the itinerary of a moving object. Trajectories pertaining to human travel or movement can be reconstructed from the data sensed in various contexts, including Global Navigation Satellite System (GNSS) tracks from vehicular or hand-held navigation devices, call detail records from mobile phone (GSM) carriers and providers, time-stamped location records from online services or social networks, and so on.

GNSS technologies allow us to record individual mobility data across entire urban network. In Italy, a sample of $3 \%$ of the whole vehicle population is monitored for insurance purposes, providing information on single trajectories with a spatial scale of $2 \mathrm{~km}$ and a time scale 30 seconds. Moreover, one datum is always recorded when the vehicle engine starts or stops. Each datum includes position, speed, motion direction, and GNSS quality. Despite the relatively poor spatial resolution of such GNSS data, it is possible to perform a real time reconstruction of the individual trajectory dynamics on the road network. Analytical detection of patterns in spatiotemporal mobility can support planning and regulation of traffic flows [12]

\subsection{Smart Grid}

The electricity demand is expected to increase globally for more than two-thirds by the year of 2035 according to the International Energy Agency. Such increase in electricity demand will put a higher burden on the current outdated and overstressed power infrastructure. The existing power grid suffers from unreliability due to the lack of efficient monitoring, fault diagnostic, and automation techniques. These problems are not related only to electrical power infrastructure but to water, gas, heat and other city infrastructures as well. Yet, the solutions for electrical power infrastructure are leading in this field. Some of the specific electrical power infrastructure related problems are unidirectional flow from the generating stations to the customers, estimation and prediction of supply based on previous available data, mechanical switches causing slow response times, and centralized generation schemes.

Smart grid has emerged to tackle these challenges, where the name suggests an intelligent power infrastructure. Smart grid technology promises to make the world power systems more secure, reliable, efficient, flexible, and sustainable. It can be defined as a modern infrastructure with efficiency and reliability enhanced through automated control, modern communication infrastructure, monitoring and measuring technologies, and advanced energy management based on demand optimization, energy and grid availability etc. $[4,5,8,11$, 24, 25].

Some of the solutions to mentioned problems propose bi-directional flow and decentralized generation scheme. A bi-directional system is an improvement to the conventional distribution scheme in the sense that electricity flows from the utility to the client's premises and vice versa. A more efficient use of energy is then possible, whereby electricity can flow back to the utility (to be stored for later use) in cases of low demand. The concept of distributed generation enables a scenario where, instead of having a centralized generation scheme, additional electricity generation points can be located closer to customers, reducing thus the impact of losses on electricity transportation over long distances. Additionally, this enables more innovative demand response programs to be put into action. Preferably, these distributed generation points could be ecological and use renewable sources like wind, sun and water energy [4, 5, 24].

In smart grid, a reliable and real-time monitoring is highly required to provide solutions quickly when natural accidents or catastrophes occur to prevent power disturbance and outage. Hence, intelligent monitoring and sensing capabilities to insure real-time response from the power grid are necessary. Wireless sensor networks can be used as compared to traditional communication technologies because of its low-cost, rapid deployment, flexibility, and aggregated intelligence via parallel processing. Data acquired by these networks can then be used as a feedback information about performances and reliability of the grid for the authorized institutions. An important sensing application in smart grid, amongst others, is the monitoring of overhead transmission lines. By monitoring the lines, utilities ensure that power delivery occurs within safe limits. For instance, systems like STAMP sense the temperature, sag and tension values of an overhead line in real time and determine the state, or health, of the line from these measurements. Apart from monitoring and controlling the grid, sensors can also be used for active monitoring of a household power consumption and thus provide savings and more dynamic billing system $[4,5]$.

\subsection{Smart Environment}

If the city is not well organized and equipped to face the stress of rapidly growing urbanization, chaos quickly 
takes place. The quality of life, the security, the effectiveness of citizens' services, the economic development and attractiveness, and the quality of the environment may decrease quickly affecting the life of the community [13].

As a solution for preserving smart city environment, a concept of smart environment is proposed, where air and water quality, temperature, humidity and other parameters would be continuously measured. In that way, the changes of environment could be tracked and pollution could be kept at a reasonable level. Special attention is paid to mitigation of emission which is a serious threat to our planet, and this is one of the main goals of smart cities. Monitoring of environment requires a large number of various sensors to be placed, mostly outdoors at locations such as parks, rivers etc. In this regard, the placement of wireless sensors on vehicles or buildings is proposed, so that air pollution in a smart city can be monitored [4, 19].

With the development of the technology, the numbers of electromagnetic fields and the mechanisms, devices and systems working in the wave base, hence the intensity of the electromagnetic field that these systems spread as well, show a rapid increase. The use of $3 \mathrm{G}$ and $4 \mathrm{G}$ systems being the new-age communication and transmission systems have caused these changes to be increased rapidly in the recent years. The physical and biological impacts of these fields on the plants and the living beings that have frequency spectrum varying generally from $\mathrm{Hz}$ to increments of $\mathrm{GHz}$ become frequently a current issue. Some other problems related to fast-growing cities are lighting systems that cause light pollution in the areas around big cities and big energy consumption, noise pollution that has negative effects on people living and working in cities, and waste management that will represent ever growing problem for cities in the future. In order to solve these problems, today's technology should be used and smart solutions found [8].

\section{DISCUSSION}

The disagreements about the terminology and definitions result from the fact that the real smart cities still do not exist in practice, but mostly at the level of ideas and partial development. Most definitions of smart cities emphasize the importance of information and computer technology in more effective management of the physical infrastructure and the environment. However, it should be added that the smart cities are a tool for improving the quality of life of people and human communities. Cities that are smart only in terms of economy are not smart at all if they ignore social conditions of their citizenry [12].

In general, every concept of spatial development (sustainable, technological, smart, etc.) should be directed to the benefit of mankind as part of nature. Sustainable development should be sustainable for humans - the preservation of the natural environment is in this function, and not a goal in itself. Thus, the development of technology should not be developed in order to replace the humans, but to serve and help them, much like Asimov set in the laws of robotics [26]. Smart development should also benefit the people. This raises the question of whether the smart cities are good for people and do we really want to live in real smart cities?
As far as sensor systems go, despite the current level of technological development, there are still some technological and conceptual problems. For example, some problems regarding quality of sensors and information they gather, determining the number of sensors for a particular application, integration of a large quantity of heterogeneous information, sensor power supply, and spatial component of the data still occur.

Although the use of as much sensors as possible for data gathering is encouraged [4], attention should be paid to the quality of the collected data and its usability. Too many redundant data are not desirable. For example, air quality is not as variable for every building to need a sensor. This would lead to too many data that would occupy memory and slow down the system, but would not contribute to the quality of the results. In addition, when selecting the sensors, one should take into consideration their purpose and quality (price to accuracy ratio). Is it really necessary to place a sensor on every flower pot in order to monitor the moisture and notify the need of watering? If the noise pollution is less important than earthquakes, should the same amount of funds be invested in both noise and seismic sensors?

Furthermore, if a large number of various sensors is placed, the problem of heterogeneity of the collected data emerges. The collected data should help the central system to make better decisions that will result in a smarter management of the city. This means that a lot of information which can have various formats, and even different spatial and temporal resolutions should be used to make unique decisions. The man's ability to make good and reasonable decisions is based on human logic and intelligence, which brings forward the concept of artificial intelligence (AI) as the solution for computer based decision making. Although there are some AI solutions available today, the AI concept is still developing and some time will pass before it really comes alive [27]. For the problems of the variability of data formats and interoperability between different systems within a smart city to be solved, norms and standards should be developed. The main global standardization organizations are following the development and issues regarding smart cities, and the corresponding standards are actively being developed [17, 27].

The wireless connection is widely accepted as a solution for the connection of sensors and sensor systems in smart cities, but the question of sensor power supply still remains. Most authors today see CMOS battery as a sensor power source, but that doesn't mean it is final or the best solution. If we are talking about a large number of sensors, it would not be convenient to have to change the batteries every now and then. Wired power supply is also problematic because it requires costly installation of the infrastructure and causes some complications in a sensor placing process. As a future solution to this problem, the concept of wireless energy transfer arises. In that way, the quality of the sensors could be increased because their functions would no longer have to be limited in order to prolong the battery life.

In the smart cities, where a large number of sensors is placed and new information is obtained every minute, it is needed for this information to be visualized. If city officials could monitor the city related information on 
some kind of a map or GIS interface, it would be easier for them to perceive this information. Also, the basic data are not sufficient for any information to be useful, thus, it is needed to connect data to the corresponding location. For example, if we measure the brightness, noise level or air quality it is necessary to know the location of this information. Spatial data are an important part of a smart city and should by no means be disregarded. Of course, it is not necessary to track the location of each sensor in real time, nor the location of each sensor needs to be determined with the same accuracy. It depends on whether the sensor is dynamic (in motion) or static, and the importance, precision, and nature of the information that is being obtained. If we have a sensor that monitors air quality and its data represent the whole neighborhood, it is sufficient to determine its position with tens of meters' accuracy, but if you adjust the traffic position of the car relative to the intersection, the accuracy of the car position should not exceed one meter. Unfortunately, it must be noted that in the most of the studied papers, there was not enough attention paid to the spatial component of the information collected by the sensors. This is probably related to the problem from the following section.

Based on viewing and analyzing all the collected literature on smart cities, a low degree of interdisciplinarity, i.e. cooperation between scientists of different scientific branches, can be noticed. Scientists are mostly focused on solving the problems more familiar to them and generally look at the problems from their branch of science standpoint. The problems of cities in general, and especially smart cities, are too complex to be solved by a single scientific branch or profession. This is often accentuated regarding security issues which are frequently overcoming other aspects of smart city. Good balance in scientific branches and professions participating in creation of smart city should ensure good balance between actors and elements of a smart city model.

\section{CONCLUSION}

Smart cities are now ubiquitous topic which is not discussed only in scientific circles, but also in the media. However, development of the concept of smart cities should be left to professionals and scientists, where especially a distinction should be made between the solutions that are really smart and those which only use modern technology in the form of integrated sensor systems and their upgrades. Yet, for the implementation of this concept, it is even desirable to include as many stakeholders as possible who are its end users. Moreover, the development should be adjusted to the physical, economic, social and other specific characteristics of individual cities.

There are several approaches regarding the issue of smart cities and sensor systems inside them, which mainly depend on the person's profession or scientific field. Sometimes the consideration about smart cities can be affected by the fact that someone is from the city, so problems of this city are closer and clearer to him. Therefore, it should be done more on the development of the interdisciplinarity and cooperation in the study of the problems of smart cities to produce more comprehensive and better solutions.

Finally, more attention should be paid to the location of the information collected by the integrated sensor systems in order for them to be effectively used in smart cities. It is the location that is one of the three major issues in modern society: what, when and where? Today, most of the information in the world has a spatial component and without it, almost all the information is not complete.

\section{REFERENCES}

[1] Al-Hader, M., Rodzi, A., Sharif, A. R. \& Ahmad, N. (2009). Smart City Components Architecture. Proceedings of the $1^{\text {st }}$ Int. Conference on Computational Intelligence, Modelling, and Simulation / Brno, 93-97.

[2] Blaschke, T., Hay, G. J., Weng, Q. \& Resch, B. (2011). Collective Sensing: Integrating Geospatial Technologies to Understand Urban Systems - An Overview. Remote Sensing, 8(3), 1743-1776 https://doi.org/10.3390/rs3081743

[3] Su., K., Li, J. \& Fu, H. (2011). Smart City and the Applications. Proceedings of the Int. Conference on Electronics. Communications and Control (ICECC) / Ningbo, 1028-1031. https://doi.org/10.1109/ICECC.2011.6066743

[4] Hancke, G. P., Carvalho e Silva, B. \& Hancke Jr., G. P. (2013). The Role of Advanced Sensing in Smart Cities. Sensors, 1(13), 393-425.

[5] Jaradat, M., Jarrah, M., Bousselham, A., Jararweh, Y. \& Al-Ayyoub, M. (2015). The Internet of Energy: Smart Sensor Networks and Big Data Management for Smart Grid. Computer Science, 1(56), 592-597. https://doi.org/10.1016/j.procs.2015.07.250

[6] Bakici, T., Almirall, E. \& Wareham, J. (2013). A Smart City Initiative: the Case of Barcelona. Journal of the Knowledge Economy, 2(4), 135-148. https://doi.org/10.1007/s13132-012-0084-9

[7] El-Sheimi, N. (2002). Report on Kinematic and Integrated Positioning Systems. Proceedings of the FIG XXII Int. Congress / Washington D.C., 1-23.

[8] Dener, M. \& Bostancioğlu, C. (2015). Smart Technologies with Wireless Sensor Networks. Procedia - Social and Behavioral Sciences, 195, 1915-1921. https://doi.org/10.1016/j.sbspro.2015.06.202

[9] Li, Y., Lin, Y. \& Geertman, S. (2015). The development of smart cities in China. Proceedings of the $14^{\text {th }}$ Int. Conference on Computers in Urban Planning and Urban Management / Cambridge, MA USA, 1-20.

[10] Harrison, C. \& Abbott Donnelly, I. (2011). A Theory of Smart Cities. Proceedings of the $55^{\text {th }}$ Annual Meeting of the ISSS / Hull, 1-15.

[11] Sánchez, L., Elicegui, I., Cuesta, J., Muñoz, L. \& Lanza, J. (2013). Integration of Utilities Infrastructures in a Future Internet Enabled Smart City Framework. Sensors, 11(13), 14438-14465. https://doi.org/10.3390/s131114438

[12] Batty, M., Axhausen, K. W., Giannotti, F., Pozdnoukhov, A., Bazzani, A., Wachowicz, M., Ouzounis, G. \& Portugali, Y. (2012). Smart cities of the future. The European Physics Journal Special Topics, 1(214), 481-518. https://doi.org/10.1140/epjst/e2012-01703-3

[13] Daniel, S. \& Doran, M. A. (2013). geoSmartCity: geomatics contribution to the Smart City. Proceedings of the $14^{\text {th }}$ Annual Int. Conference on Digital Government Research / Quebec City, 65-71. https://doi.org/10.1145/2479724.2479738

[14] Sagl, G., Resch, B. \& Blaschke, T. (2015). Contextual Sensing: Integrating Contextual Information with Human and Technical Geo-Sensor Information for Smart Cities. Sensors, 7(15), 17013-17035. https://doi.org/10.3390/s150717013 
[15] Gaur, A. \& Scotney, B. (2015). Smart City Architecture and its Applications based on IoT. Computer Science, 1(52), 1089-1094. https://doi.org/10.1016/j.procs.2015.05.122

[16] Giffinger, R. \& Haindlmaier, G. (2010). Smart cities ranking: an effective instrument for the positioning of the cities? Architecture, City and Environment, 12(4), 7-26.

[17] ISO/IEC. Smart cities Preliminary Report 2014. ISO copyright office, Geneva, 2015.

[18] Filipponi, L., Vitaletti, A., Landi, G., Memeo, V., Laura, G. \& Pucci, P. (2010). Smart City: An Event Driven Architecture for Monitoring Public Spaces with Heterogeneous Sensors. Proceedings of the Fourth Int. Conference on Sensor Technologies and Applications / Venice, 281-286. https://doi.org/10.1109/SENSORCOMM.2010.50

[19] Brienza, S., Galli, A., Anastasi, G. \& Bruschi, P. (2015). A Low-Cost Sensing System for Cooperative Air Quality Monitoring in Urban Areas. Sensors, 6(15), 12242-12259. https://doi.org/10.3390/s150612242

[20] Al-Hader, M. \& Rodzi, A. (2009). The smart city infrastructure development \& monitoring. Theoretical and Empirical Researches in Urban Management, 12(2), 87-94.

[21] Leccese, F., Cagnetti, M. \& Trinca, D. (2014). A Smart City Application: A Fully Controlled Street Lighting Isle Based on Raspberry-Pi Card, a ZigBee Sensor Network and WiMAX. Sensors, 12(14), 24408-24424. https://doi.org/10.3390/s141224408

[22] Mora-Mora, H., Gilart-Iglesias, V., Gil, D. \& SirventLlamas, A. (2015): A Computational Architecture Based on RFID Sensors for Traceability in Smart Cities. Sensors, 6(15), 13591-13626. https://doi.org/10.3390/s150613591

[23] Poslad, S., Ma, A., Wang, Z. \& Mei, H. (2015). Using a Smart City IoT to Incentivise and Target Shifts in Mobility Behaviour - Is It a Piece of Pie? Sensors, 6(15), 1306913096. https://doi.org/10.3390/s150613069

[24] Qi, W., Liu, J. \& Christofides, P. D. (2011). A distributed control framework for smart grid development: Energy/water system optimal operation and electric grid integration. Journal of Process Control, 10(21), 1504-1516. https://doi.org/10.1016/j.jprocont.2011.05.010

[25] Güngör, V. C., Sahin, D., Kocak, T., Ergüt, S., Buccella, C., Cecati, C. \& Hancke, G. P. (2011). Smart Grid Technologies: Communication Technologies and Standards. IEEE Transactions on industrial informatics, 7(4), 529-539. https://doi.org/10.1109/TII.2011.2166794

[26] Asimov, I. ( 1950). Robot. New York: Gnome Press.

[27] European Standardization Organization (CEN). SSCC-CG Final report: Smart and Sustainable Cities and Communities Coordination Group. 2015. ftp://ftp.cencenelec.eu/EN/ EuropeanStandardization/Fields/SmartLiving/City/SSCCCG_Final_Report-recommendations_Jan_2015.pdf (20.08.2016).

\section{Contact information:}

\section{Željko BAČlć, PhD, Full Professor}

Faculty of Geodesy, University of Zagreb

Kačićeva 26, 10000 Zagreb, Croatia

E-mail: zbacic@geof.hr

\section{Tomislav JOGUN, MSc}

Faculty of Geodesy, University of Zagreb

Kačićeva 26, 10000 Zagreb, Croatia

E-mail: tjogun@geof.hr

\section{Ivan MAJIĆ, MSc}

Faculty of Geodesy, University of Zagreb

Kačićeva 26, 10000 Zagreb, Croatia

E-mail: imaji@@geof.hr 